\title{
Discordant Ventriculoarterial Connection
}

National Cancer Institute

\section{Source}

National Cancer Institute. Discordant Ventriculoarterial Connection. NCI Thesaurus. Code C98914.

A rare congenital cardiovascular abnormality in which the aorta arises from the right ventricle and the pulmonary artery arises from the left ventricle. 